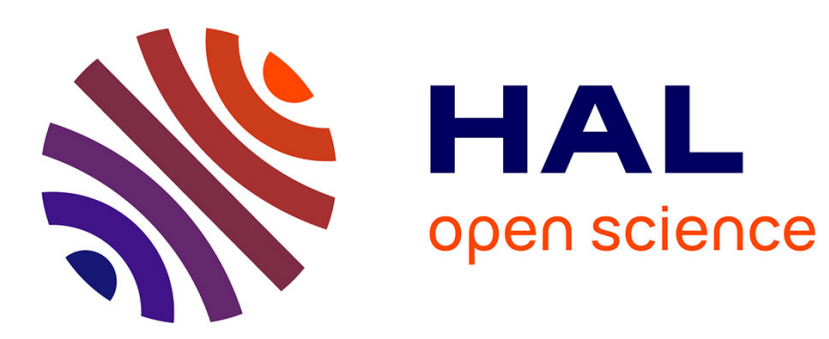

\title{
The roles of aerosol, water vapor and cloud in future global dimming/brightening
}

J.M. Haywood, N. Bellouin, A. Jones, Olivier Boucher, M. Wild, K.P. Shine

\section{To cite this version:}

J.M. Haywood, N. Bellouin, A. Jones, Olivier Boucher, M. Wild, et al.. The roles of aerosol, water vapor and cloud in future global dimming/brightening. Journal of Geophysical Research: Atmospheres, 2011, 116 (20), pp.D20203. 10.1029/2011JD016000 . hal-01120525

\section{HAL Id: hal-01120525 \\ https://hal.science/hal-01120525}

Submitted on 25 Feb 2015

HAL is a multi-disciplinary open access archive for the deposit and dissemination of scientific research documents, whether they are published or not. The documents may come from teaching and research institutions in France or abroad, or from public or private research centers.
L'archive ouverte pluridisciplinaire HAL, est destinée au dépôt et à la diffusion de documents scientifiques de niveau recherche, publiés ou non, émanant des établissements d'enseignement et de recherche français ou étrangers, des laboratoires publics ou privés. 


\title{
The roles of aerosol, water vapor and cloud in future global dimming/brightening
}

\author{
Jim M. Haywood, ${ }^{1,2}$ Nicolas Bellouin, ${ }^{1}$ Andy Jones, ${ }^{1}$ Olivier Boucher, ${ }^{1,3}$ Martin Wild, ${ }^{4}$
} and Keith P. Shine ${ }^{5}$

Received 24 March 2011; revised 28 July 2011; accepted 3 August 2011; published 22 October 2011.

[1] Observational evidence indicates significant regional trends in solar radiation at the surface in both all-sky and cloud-free conditions. Negative trends in the downwelling solar surface irradiance (SSI) have become known as 'dimming' while positive trends have become known as 'brightening'. We use the Met Office Hadley Centre HadGEM2 climate model to model trends in cloud-free and total SSI from the pre-industrial to the present-day and compare these against observations. Simulations driven by CMIP5 emissions are used to model the future trends in dimming/brightening up to the year 2100 . The modeled trends are reasonably consistent with observed regional trends in dimming and brightening which are due to changes in concentrations in anthropogenic aerosols and, potentially, changes in cloud cover owing to the aerosol indirect effects and/or cloud feedback mechanisms. The future dimming/brightening in cloud-free SSI is not only caused by changes in anthropogenic aerosols: aerosol impacts are overwhelmed by a large dimming caused by increases in water vapor. There is little trend in the total SSI as cloud cover decreases in the climate model used here, and compensates the effect of the change in water vapor. In terms of the surface energy balance, these trends in SSI are obviously more than compensated by the increase in the downwelling terrestrial irradiance from increased water vapor concentrations. However, the study shows that while water vapor is widely appreciated as a greenhouse gas, water vapor impacts on the atmospheric transmission of solar radiation and the future of global dimming/brightening should not be overlooked.

Citation: Haywood, J. M., N. Bellouin, A. Jones, O. Boucher, M. Wild, and K. P. Shine (2011), The roles of aerosol, water vapor and cloud in future global dimming/brightening, J. Geophys. Res., 116, D20203, doi:10.1029/2011JD016000.

\section{Introduction}

[2] Observational evidence has accumulated indicating the amount of solar radiation incident at the surface of the Earth has fluctuated on decadal timescales [e.g., Ohmura and Lang, 1989; Gilgen et al., 1998; Stanhill and Cohen, 2001; Liepert, 2002; Wild et al., 2005]. The term 'global dimming' has become synonymous with the observed widespread decrease in SSI [Stanhill and Cohen, 2001; Wild, 2009] but the phenomenon is far from being spatially coherent with significant regional differences in both the magnitude and the sign of the trends [e.g., Wild et al., 2005].

[3] Many sites show a dimming pre-1980s but the trend subsequently reverses leading to a brightening at some of the sites. Wild [2009] summarize a great number of studies

\footnotetext{
${ }^{1}$ Hadley Centre, Met Office, Exeter, UK.

${ }^{2}$ Exeter Climate Systems, College of Engineering, Mathematics and Physical Science, University of Exeter, Exeter, UK.

${ }^{3}$ Laboratoire de Météorologie Dynamique, CNRS/UPMC, Paris, France.

${ }^{4}$ Institute for Atmospheric and Climate Science, ETH Zurich, Zurich, Switzerland.

${ }^{5}$ Department of Meteorology, University of Reading, Reading, UK.
}

Copyright 2011 by the American Geophysical Union. 0148-0227/11/2011JD016000 finding trends of around -1.6 to $-5.1 \mathrm{~W} \mathrm{~m}^{-2} /$ decade globally over the period of roughly 1960s-1980s. Wild [2009] reports trends of -2 to $-10 \mathrm{~W} \mathrm{~m}^{-2}$ /decade for European locations, -2.6 to $-6 \mathrm{~W} \mathrm{~m}^{-2} /$ decade for North America and -1 to $-8 \mathrm{~W} \mathrm{~m}^{-2}$ /decade for Asia (with the exception of the study by Stanhill and Kalma [1995] who report a trend of $-18 \mathrm{~W} \mathrm{~m}^{-2}$ / decade for Hong Kong). Even polar regions show a reported dimming trend of -2.8 to $-3.6 \mathrm{~W} \mathrm{~m}^{-2}$ /decade. Wild [2009] finds that around the $1980 \mathrm{~s}$ the trends typically reverse from a dimming to a brightening and report trends of between +2.2 to $+6.6 \mathrm{~W} \mathrm{~m}^{-2} /$ decade over the period $1980 \mathrm{~s}-2000 \mathrm{~s}$. However, once again local/regional trends vary significantly: Wild [2009] reports brightening trends of +1.4 to $+4.9 \mathrm{~W} \mathrm{~m}^{-2}$ / decade for Europe, +2 to $+8 \mathrm{~W} \mathrm{~m}^{-2} /$ decade for North America, and +2.7 to $+8 \mathrm{~W} \mathrm{~m}^{-2} /$ decade for Asia (with the exception of sites in India, which show continued dimming of $-8.6 \mathrm{~W} \mathrm{~m}^{-2} /$ decade [Padma Kumari et al., 2007] and a renewed dimming trend of $-4.2 \mathrm{~W} \mathrm{~m}^{-2} /$ decade in China after 2000 [Wild et al. 2009]).

[4] Some significant efforts have been made to separate the dimming and brightening trends in the total SSI (those reported in the previous paragraph) at the surface into cloudfree and cloudy-sky conditions using high temporal resolution radiation measurements. Wild et al. [2005, 2009] found brightening trends in the cloud-free SSI of between +4.9 to 
$6.7 \mathrm{~W} \mathrm{~m}^{-2} /$ decade in the baseline surface radiation network (BSRN) in the 10-13 year period from 1992 depending on the sites analyzed. Wild [2009] concludes that a similar picture can be drawn from the analyses of cloud-free SSI trends to the analyses of total SSI: dimming trends exist before the mid 1980s followed by brightening trends.

[5] There are a variety of mechanisms that can potentially contribute to both dimming and brightening. Kvalevaig and Myhre [2007] considered a range of contributors to dimming since pre-industrial times. While the major contributor to the global-mean value of $-2.4 \mathrm{~W} \mathrm{~m}^{-2}$ was aerosols $\left(-1.4 \mathrm{~W} \mathrm{~m}^{-2}\right.$ due to the direct aerosol effect and $-0.7 \mathrm{Wm}^{-2}$ due to the indirect aerosol effect), there was a non-negligible effect of changes in gas concentrations: the total gaseous dimming was $-0.64 \mathrm{~W} \mathrm{~m}^{-2}$ due primarily to tropospheric ozone and water vapor increases, with lesser contributions from changes in $\mathrm{NO}_{2}, \mathrm{CH}_{4}$ and $\mathrm{CO}_{2}$, which were offset by a brightening of $0.33 \mathrm{~W} \mathrm{~m}^{-2}$ due to stratospheric ozone depletion. Similarly, Romanou et al. [2007] analyze results from the GISS model over the 20th Century and find that the aerosol direct effect contributes most to the modeled dimming, followed by the aerosol indirect effect. Potentially, changes in top-of-atmosphere incoming solar irradiance could contribute to dimming and brightening, but given that changes over the course of an 11-year solar cycle are $\sim 0.1 \%$ (and much of this is concentrated in the UV and does not reach the surface) such variations are likely to cause changes of $\sim 0.1 \mathrm{Wm}^{-2}$ [Gray et al., 2009]. Here, we restrict our attention primarily to those caused by change in aerosols, water vapor and clouds.

[6] We examine whether observed trends are represented by a state-of-the-science climate model, then continue the model simulations into the future using two different climate scenarios: one where concentrations of greenhouse gases increase slowly and peak in the 2050s, and one where greenhouse gases increase rapidly throughout the 21 st century. Section 2 describes the model and the methodology used and section 3 investigates the dimming and brightening trends in the model and compares these against the observations summarized by Wild [2009]. Section 4 investigates future modeled trends in total SSI and examines the causes of these trends. A discussion and conclusions are provided in section 5 .

\section{Method}

[7] HadGEM2-ES [Collins et al., 2011] is the most recent version of the fully coupled atmosphere-ocean climate model that has been developed by the Met Office Hadley Centre. The atmospheric component has 38 levels extending to $\sim 40 \mathrm{~km}$ height, with a horizontal resolution of $1.25^{\circ} \times 1.875^{\circ}$ latitude and longitude respectively, equivalent to a surface resolution of about $208 \mathrm{~km} \times 139 \mathrm{~km}$ at the Equator, reducing to $120 \mathrm{~km} \times 139 \mathrm{~km}$ at $55^{\circ}$ latitude. The 'ES' refers to the Earth System version of the model which includes coupling to the carbon cycle, which allows the incorporation of biogeochemical feedbacks which can damp or amplify the climate sensitivity to different external forcing mechanisms. The model includes the Coupled Large-scale Aerosol Simulator for Studies In Climate (CLASSIC) aerosol scheme which includes external mixtures of sulphate, fossil-fuel black carbon, fossil-fuel organic carbon, biomass burning aerosol, biogenic organic aerosol, mineral dust and sea-salt [Bellouin et al., 2008]. Nitrate has recently been added to CLASSIC [Bellouin et al., 2011], but this aerosol species is not included in our simulations. Trends in emissions and AODs for each natural and anthropogenic aerosol species are reported in detail by Bellouin et al. [2011], and are not reported in detail here. The radiation code within HadGEM2 [Edwards and Slingo, 1996] explicitly includes the scattering and absorption of solar and terrestrial radiation by aerosols and the first (cloud albedo) and second (cloud lifetime) effects [Forster et al., 2007]. The indirect effects are included via an empirical relationship between aerosol concentration and cloud droplet number concentration [Jones et al., 2001] which subsequently suppresses cloud droplet autoconversion and precipitation leading to an increase in cloud liquid water content, cloud lifetime, and fractional cloud cover.

[8] HadGEM2-ES is forced using the Climate Model Intercomparison Project phase 5 (CMIP5) protocol using historical data from 1860 to 2005 and Representative Concentration Pathway (RCP) scenarios [Moss et al., 2010] up to 2100. Pathways of well mixed GHG concentrations $\left(\mathrm{CO}_{2}\right.$, $\mathrm{CH}_{4}, \mathrm{~N}_{2} \mathrm{O}$ and halocarbons) are prescribed [Meinshausen et al., 2011] as are emissions of aerosols or their precursors for sulphate, fossil-fuel black and organic carbon, and biomass aerosols [Lamarque et al., 2010]. Sea-salt and mineral dust aerosol emissions are simulated interactively according to climate conditions in the model. Non-transported jet and film mode sea salt concentrations are a function of wind speed [Jones et al., 2001; Bellouin et al., 2008]. Mineral dust is transported in 6 discrete size bins and its generation is a function of the surface threshold friction velocity, soil type, vegetative fraction, and soil moisture [Woodward, 2001]. Tropospheric ozone is simulated by the model using the UKCA chemistry scheme with surface and aircraft emissions of tropospheric ozone precursors and reactive gases. Stratospheric ozone is prescribed as monthly zonal/height fields [Cionni et al., 2011] which cover the period 1850 to 2100. Land-cover is simulated by the model's dynamic vegetation scheme but also forced by scenarios of anthropogenic landuse change to represent deforestation and changes in agricultural extent [Hurtt et al., 2011]. Natural climate forcings are represented by prescribing time-varying changes in total solar irradiance (J. L. Lean, http://www.geo.fu-berlin.de/en/ met/ag/strat/forschung/SOLARIS/Input data/Calculations of Solar Irradiance.pdf, last accessed 2 June 2009) and monthly volcanic perturbations to stratospheric aerosols in 4 equalarea latitudinal bands use data from Sato et al. [1993] with updates for the period 1990-2005 (http://data.giss.nasa.gov/ modelforce/strataer/). To represent natural forcing in the future scenarios, and to prevent a discontinuity due to a sudden change in forcing after 2005, the last solar cycle is repeated and volcanic forcing is reduced smoothly to a background value. See Jones et al. [2011] for a full description of the scenarios and how they are implemented. This historical simulation is referred to as 'HIST'. A simulation (AER1860) is also performed where only natural forcings and greenhouse gas emissions are applied from pre-industrial times while anthropogenic emissions of aerosols are fixed at 1860 levels. A further control simulation where no external forcing mechanisms are applied (CNTL) is performed to diagnose the natural variability by diagnosing trends in decadal 10-year running means and determining the standard 


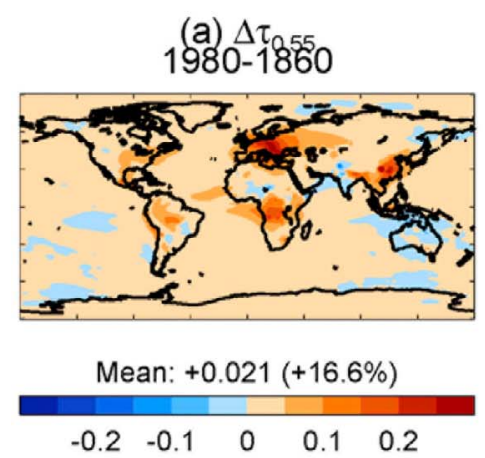

(c) $\Delta \mathrm{F}$ (down, clear, SW) $1980-1860$
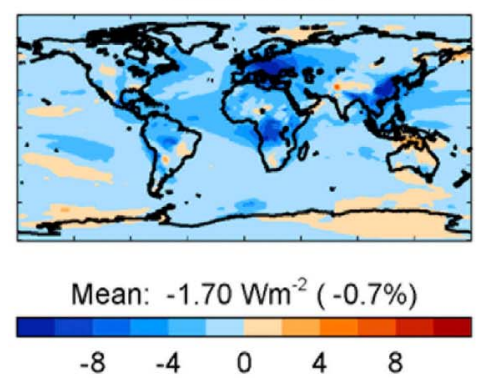

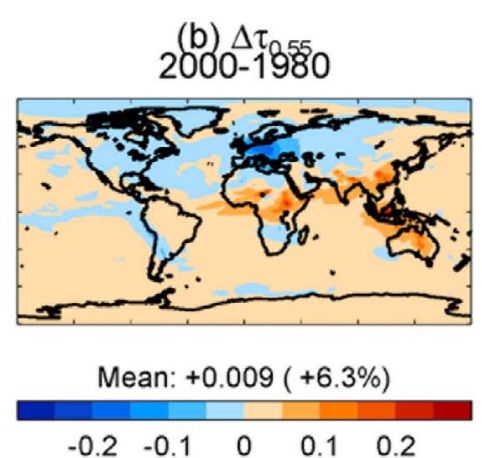

(d) $\Delta \mathrm{F}$ (down, clear, SW) 2000-1980

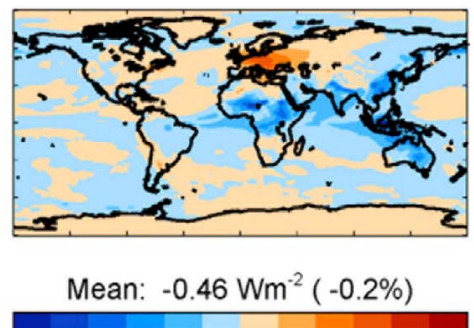

$\begin{array}{lllll}-8 & -4 & 0 & 4 & 8\end{array}$

Figure 1. Change in the modeled annual-mean AOD at $0.55 \mu \mathrm{m}$ over the period (a) 1980-1860 and (b) 2000-1980, and (c, d) the corresponding changes in the cloud-free SSI ( $\mathrm{W} \mathrm{m}^{-2}$ ). The results are compiled from five-year means centered on 1860, 1980, and 2000 as appropriate.

deviation $(\sigma)$ in these trends. We use $2 \sigma$ as a measure of statistical significance.

[9] Two different scenarios are considered here to approximately encompass the range of future temperature change: the RCP3-PD ("Peak and Decline") and RCP8.5 scenarios. The first yields a future change in global-mean temperatures of $+1.8 \mathrm{~K}$ relative to pre-industrial times by 2100 , having peaked at $+2 \mathrm{~K}$ in 2050 , while the second produces a global-mean temperature change of $+5.2 \mathrm{~K}$ relative to pre-industrial times by 2100 . All-sky and cloud-free fluxes are diagnosed by the radiation scheme by including/ excluding the extinction of radiation by cloud droplets and ice crystals in the calculation of atmospheric transmission. This method of diagnosing the cloud-free SSI uses the grid-box mean specific humidity as standard. Additional diagnostics were developed to diagnose the SSI using the specific humidity in cloud-free areas of the grid-box. When we present geographical distributions of the modeled trends we focus mainly on the cloud-free radiation budget to remove the variability of clouds from the simulations, and we show results based on five-year means. However, despite the noise in the simulations when clouds are considered, the trends in the total SSI can be isolated at regional scales when appropriately large regional averages are made.

\section{Geographic Distribution and Temporal Evolution of Dimming/Brightening: The Past}

[10] The changes in AOD at a wavelength of $0.55 \mu \mathrm{m}$ and the corresponding changes in the cloud-free SSI for the periods 1860-1980 and 1980-2000 are shown in Figure 1.
[11] Figure 1a shows that the AOD increases significantly over the 1860 to 1980 period in industrialized regions of North America, Europe and South-East Asia and the biomass-burning regions of Africa and South America where there are increases in anthropogenic aerosol emissions [Lamarque et al., 2010]. Figure 1b shows significant decreases in AOD between 1980 and 2000 over Europe and smaller decreases over large parts of the northern hemisphere extra-tropical land regions, but continued increases over central Africa, South-East Asia and Indonesia. Figures 1c and 1d show that the cloud-free changes in the SSI follow the changes in AOD closely (with opposite sign). Figure 2 shows a scatterplot of the change in the cloud-free SSI as a function of the change in the AOD at $0.55 \mu \mathrm{m}$ for the periods 1980-1860 and 2000-1980.

[12] Figures $2 \mathrm{a}$ and $2 \mathrm{~b}$ show an almost linear relationship with a combined sensitivity of around $-50 \mathrm{Wm}^{-2} / \mathrm{AOD}$ and an intercept that has a statistically negligible difference from zero. This modeled sensitivity is slightly more negative than the $-41 \mathrm{Wm}^{-2}$ /AOD that has been determined experimentally for volcanic aerosols in solar radiation measurements in Japan [Stanhill and Cohen, 2008]; these slight difference could be due to anthropogenic aerosols including absorbing components like black carbon and consequently a lower single scattering albedo [Bellouin et al., 2008].

[13] To provide a more detailed comparison of the model simulations against observations, we investigate the temporal evolution of dimming/brightening trends over three specific regions: global, Europe $\left(40^{\circ} \mathrm{N}-60^{\circ} \mathrm{N}, 10^{\circ} \mathrm{W}-30^{\circ} \mathrm{E}\right)$ and South-East Asia $\left(10^{\circ} \mathrm{N}-40^{\circ} \mathrm{N}, 70^{\circ} \mathrm{E}-135^{\circ} \mathrm{E}\right)$; regions where several long-term observation studies have been carried out 

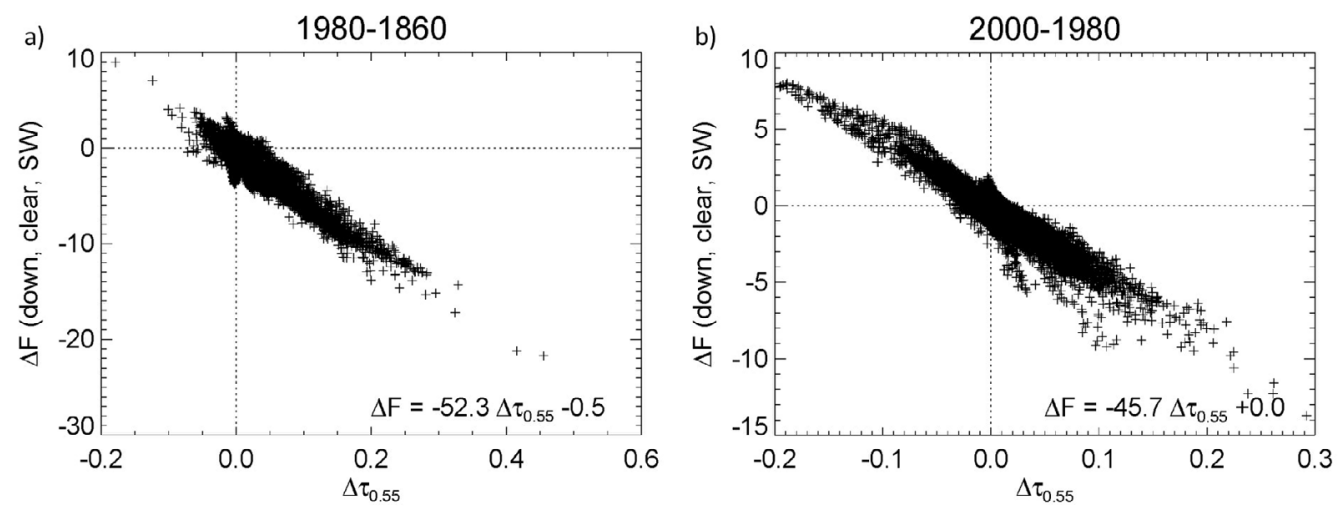

Figure 2. Scatterplots of the change in modeled annual mean cloud-free SSI $\left(\mathrm{W} \mathrm{m}^{-2}\right)$ as a function of the change in the AOD $\left(\tau_{0.55}\right)$. (a) 1980-1860, (b) 2000-1980.

[see Wild, 2009, Tables 1 and 2]. The studies listed by Wild [2009] quantify dimming and brightening trends and transitions between the two by determining the year of the minimum in the observed total SSI. We only analyze model data over land areas as the observational sites are all land based. The results will be influenced by the exact choices of geographic area and time period over which dimming/ brightening trends are assessed. We present the mean decadal trends in 10-year running mean data over these geographic areas, and probability distribution functions (PDFs) of the trends using the data points from within the defined areas, so that the variability within the areas can be assessed.

[14] Figure 3 shows the temporal evolution of the cloud-free SSI in $\mathrm{Wm}^{-2}$ for global, Europe and South-East Asia, and corresponding trends in 10-year running means in $\mathrm{Wm}^{-2} /$ decade.

[15] Figure 3a clearly shows the decreased global mean cloud-free SSI owing to the volcanic eruptions of Agung in 1963, El Chichón in 1982, and Pinatubo in 1991 are represented with deviations from the 10 -year mean running average of $-1.3 \mathrm{Wm}^{-2},-2.3 \mathrm{Wm}^{-2}$, and $-3.0 \mathrm{Wm}^{-2}$ respectively in HIST. The statistically significant peak cloud-free global mean decadal dimming in HIST occurs in the 1980s when it reaches $-1.5 \mathrm{Wm}^{-2} /$ decade (Figure $3 \mathrm{~d}$ ), followed by a brightening in the 1990 s of up to $1.4 \mathrm{Wm}^{-2} /$ decade. A weaker, but statistically significant dimming is also evident in AER1860 with a peak dimming reaching $-0.8 \mathrm{Wm}^{-2} /$ decade in the 1980 s and a peak brightening reaching $1.3 \mathrm{Wm}^{-2} /$ decade in the $1990 \mathrm{~s}$. Statistically significant trends in AER1860 only occur in the 1960s and 1980s which suggests that the volcanic eruptions of Agung, El Chichón and Pinatubo can significantly influence decadal trends in the model.

[16] Over Europe, Figure 3b shows a difference in the cloud-free SSI in HIST and AER1860 by 1920 because aerosols in Europe have already caused a dimming in HIST. HIST shows a modeled trend of on average $-0.9 \mathrm{Wm}^{-2}$ / decade from 1930 to 1980 with a maximum dimming of $-2.4 \mathrm{Wm}^{-2} /$ decade during the 1960 s (Figure 3e) followed by a brightening as strong as $4.0 \mathrm{Wm}^{-2} /$ decade during the late 1990s. AER1860 shows a statistically significant brightening trend of $1.1 \mathrm{Wm}^{-2} /$ decade in the 1990s again suggesting the brightening in Europe in the model is due in part to the fading impacts of volcanic aerosols.
[17] Over South-East Asia, HIST shows no statistically significant trend before 1970 before two decades of statistically significant dimming during the 1970s and 1980s with a peak dimming of up to $-3.0 \mathrm{Wm}^{-2} /$ decade, while AER1860 shows no significant trends.

[18] The majority of observational studies have only diagnosed the change in the total SSI, (rather than cloud-free SSI) including the effects of clouds [Wild, 2009]. The temporal evolution of the total SSI and corresponding trends are shown in Figure 4.

[19] The influence of the volcanic eruptions is still clearly visible in the global mean data shown in Figure 4a, but the regional SSI shows considerably more variability owing to the inclusion of clouds. Globally, HIST shows a statistically significant dimming trend of on average around $-0.7 \mathrm{Wm}^{-2}$ / decade from 1960 to 1990, with a peak dimming of $-1.3 \mathrm{Wm}^{-2} /$ decade during the $1960 \mathrm{~s}$, followed by a peak brightening of around $1.3 \mathrm{Wm}^{-2} /$ decade in the $1990 \mathrm{~s}$ (Figure 4d). The overall dimming from 1920 to 2000 from HIST is approximately $-2.0 \mathrm{Wm}^{-2}$, which is in agreement with the analysis of 10 model simulations from IPCC 4AR which produced dimmings ranging from -1 to $-4 \mathrm{Wm}^{-2}$ over the 20th Century [Romanou et al., 2007]. AER1860 suggests that the brightening in the 1990s in the model is due to the reduction in stratospheric volcanic AOD. For Europe (Figures $4 \mathrm{~b}$ and $4 \mathrm{e}$ ) under HIST, the peak decadal dimming reaches $-4.5 \mathrm{Wm}^{-2} /$ decade around 1954 and $-3.9 \mathrm{Wm}^{-2}$ / decade around 1970 before a peak brightening of $5.1 \mathrm{Wm}^{-2}$ / decade in 1986. For South-East Asia, Figure 4f shows the dimming trend in HIST reaches a statistically significant $-3.4 \mathrm{Wm}^{-2} /$ decade in the late $1980 \mathrm{~s}$. This suggests that the peak dimming in South East Asia in the model occurs some 10-15 years later than in Europe.

[20] The diagnosed trends will depend upon the spatial areas, start and end periods, and the timing of sporadic events such as volcanic eruptions within the decade [e.g., Weatherhead et al., 2002]. In addition, observed trends consist of a series of point measurements made within each of the areas, and may not be representative of the area as a whole. To make a more representative analysis which includes the spatial variability of the trends, we analyze the model dimming (1960-1980) and brightening (1980-2000) trends in Europe and the dimming (1960-1990) and bright- 


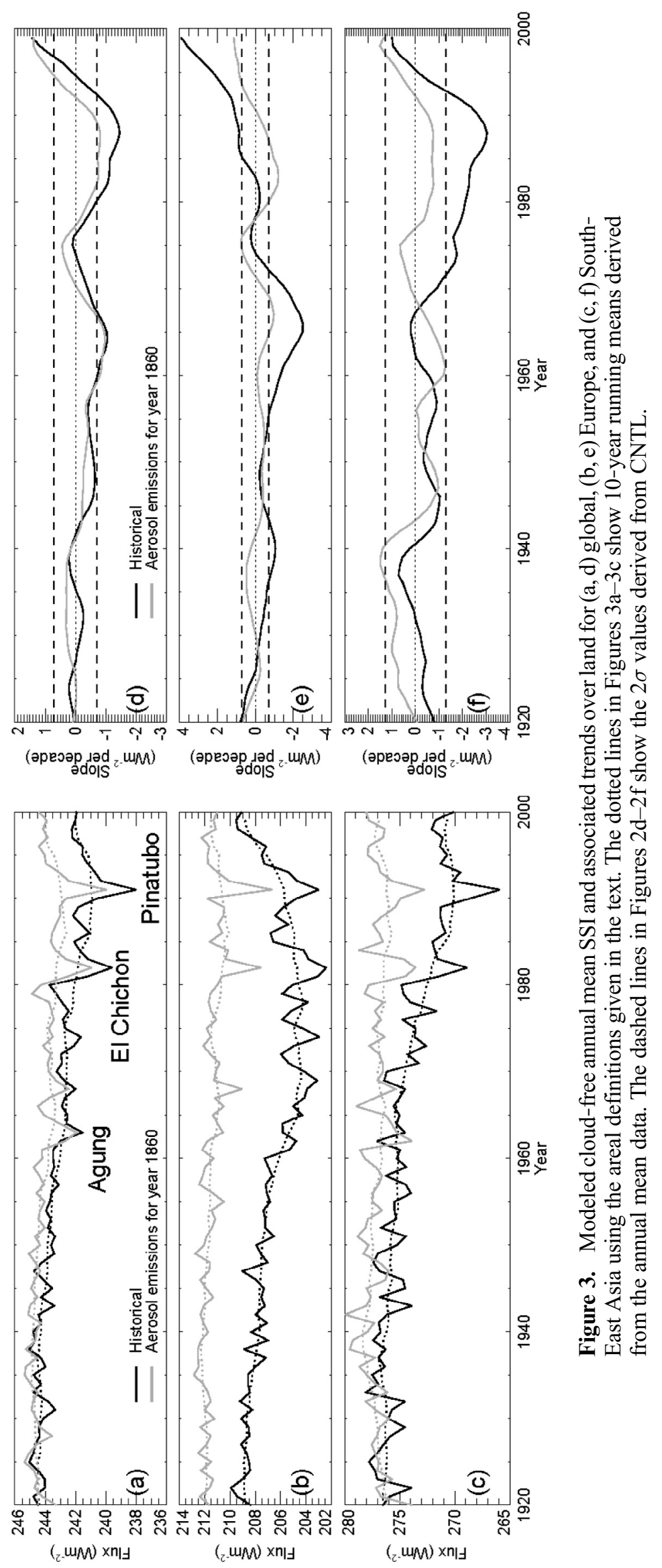




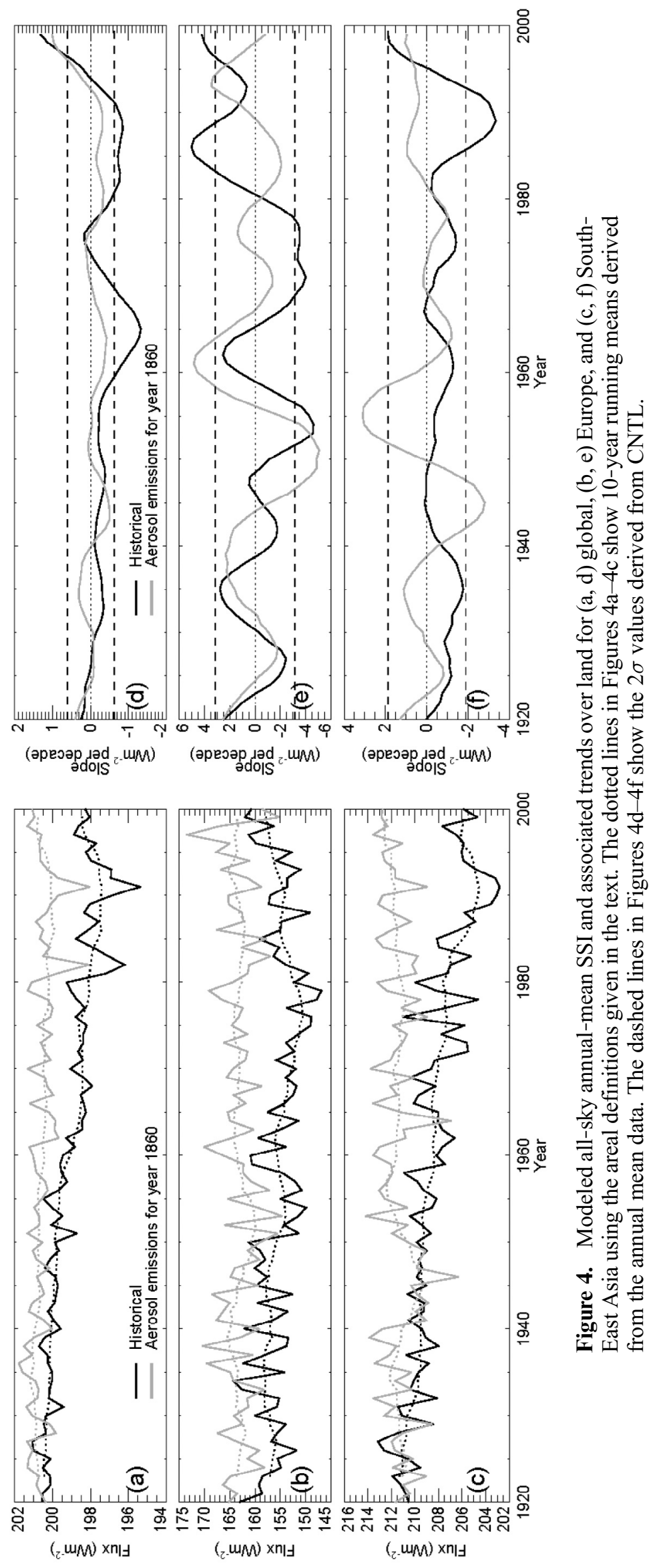



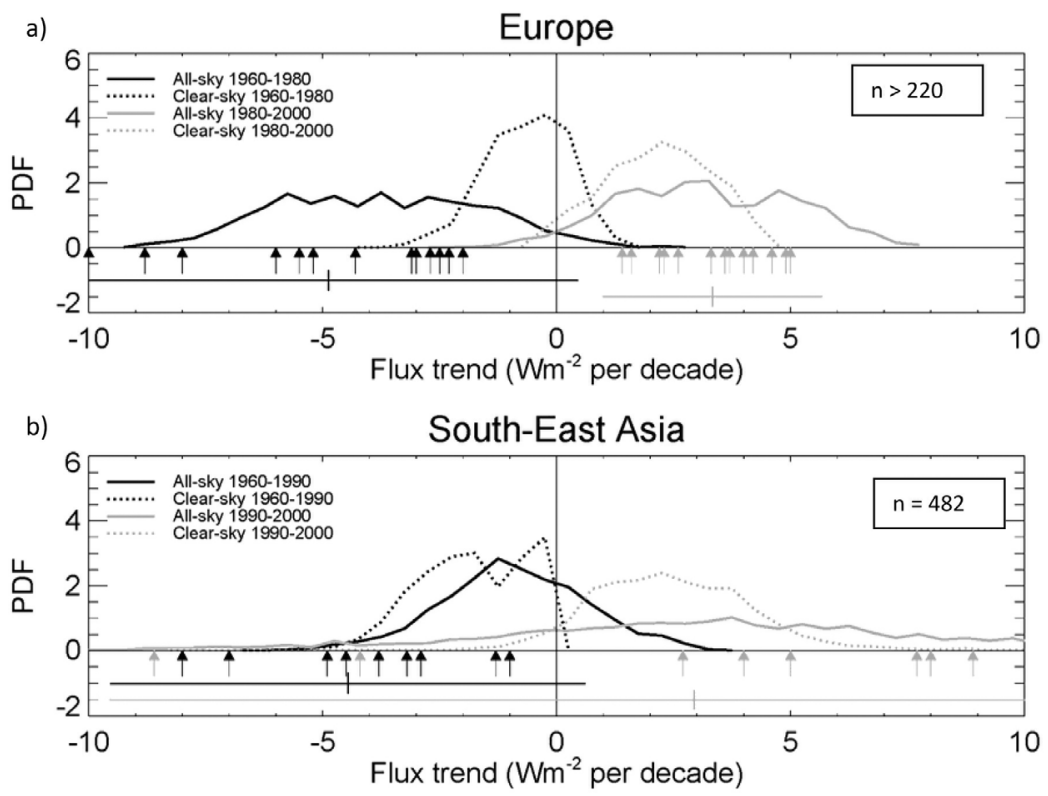

Figure 5. Modeled probability distribution functions of the trends in dimming/brightening over (a) Europe and (b) South-East Asia. The black lines represent the period 1960-1980 for Europe and the period 19601990 for South-East Asia. The gray lines represent the period 1980-2000 for Europe and 1990-2000 for South-East Asia. Total SSI trends are shown by the solid lines and cloud-free SSI trends are shown by the dotted lines. For each case the mean PDF for each area use start and end points that vary by \pm 2 years as described in the text. The arrows represent the observed trends in the total SSI determined by the studies listed in Tables 1 and 2 of Wild [2009]. Each of the arrows represents the mean from multiple stations. The total number of stations is given by $\mathrm{n}$. The vertical and horizontal lines under the abscissa represent the mean and $2 \sigma$ from the observations.

ening (1990-2000) trends in South-East Asia by producing PDFs derived from individual grid-boxes. To reduce the variability in the total SSI trends caused by the interannual variability, we make a mean PDF for each area using start and end points that vary by \pm 2 years. For example, the PDF generated for the dimming period for Europe is generated from the mean PDF of 1958-1978, 1959-1979, 1960-1980, 1961-1981, and 1962-1982. The PDFs for Europe and South-East Asia are shown in Figures 5a and 5b, respectively. These figures also show the observed trends in total SSI diagnosed from Tables 1 and 2 of Wild [2009].

[21] The PDF for Europe for 1960-1980 (Figure 5a) shows a pronounced dimming in the total SSI while the cloud-free SSI shows lesser trends. This suggests that the trends in total SSI are influenced not just by the aerosol direct effect on the atmospheric transmission, but also by trends in cloud amount and/or optical thickness (see also Figures 3 and 4). The model displays a mean trend in cloud fraction over Europe of around $+2 \%$ over the period. This change in cloud fraction may be due to factors such as an increased aerosol indirect effect which will tend to increase the lifetime of clouds [e.g., Haywood and Boucher, 2000], natural variability, or complex cloud feedbacks in response to increased greenhouse gas concentrations and the associated warming. Definitive attribution of the impacts of aerosol indirect forcing and natural cloud variability and cloud feedbacks is not possible from the limited number of model simulations and would require a far more complex experimental design. Interestingly, the observed trends in Figure 5a, show a greater degree of consistency with the PDF for the total SSI than the cloud-free
SSI. The PDF for 1980-2000 shows a more pronounced brightening in the total SSI than for the cloud-free SSI: once again the observed trends are more consistent with the trends in the total SSI than the cloud-free SSI. Again, factors such as a reduced aerosol indirect effect, natural cloud variability or cloud feedbacks may play a role.

[22] The PDF for South-East Asia shows a dimming for the period 1960-1990 for both the cloud-free and total SSI. The consistency with observations is less clear than that shown for Europe. Generally, the observations suggest a period of dimming pre-1990 ranging from -1 to $-8 \mathrm{~W} \mathrm{~m}^{-2}$ /decade, but post-1990 the observations suggest a very wide range from a dimming of $-9 \mathrm{~W} \mathrm{~m}^{-2} /$ decade to a brightening of $+9 \mathrm{~W} \mathrm{~m}^{-2}$ / decade. The model results suggest that the magnitude of the observed dimming is inadequately represented, but the wide range of observed dimming/brightening trends are also evident in the model.

[23] The model simulations appears to be more consistent with observations when both changes in the turbidity of the atmosphere and changes in clouds are considered. The consistency of the model results with the observations is pleasing given that other studies have shown a poorer agreement when considering the impacts of total SSI including the impacts of clouds [Wild and Schmucki, 2011].

\section{Geographic Distribution and Temporal Evolution of Dimming/Brightening: The Future}

[24] Figures 6a and $6 \mathrm{~b}$ show the change in the AOD between 2000 and 2090 under the RCP3-PD and RCP8.5 

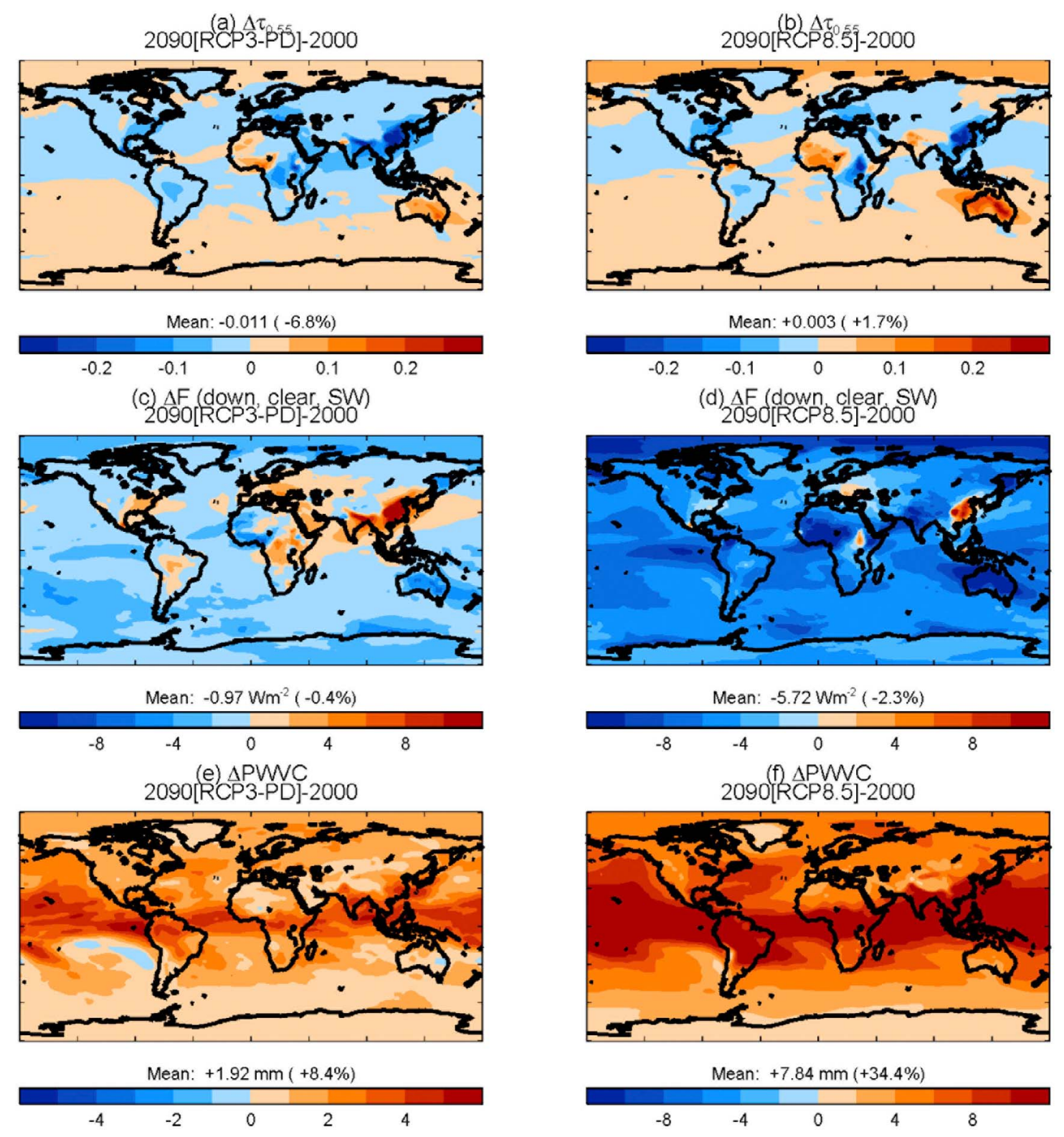

Figure 6. Modeled change in annual mean AOD between 2090 and 2000 for (a) RCP3-PD and (b) RCP8.5 scenarios; $(c, d)$ the corresponding changes in SSI; $(e, f)$ the corresponding changes in precipitable water $\left(\mathrm{kg} \mathrm{m}^{-2}\right)$. The results are compiled from five-year means centered on 2000 and 2090 as appropriate.

scenarios which indicate that anthropogenic aerosol AODs are predicted to decrease over this time period. The decreases in AOD over Europe for the period 1980 to 2000 shown in Figure $1 \mathrm{~b}$ continue while the increases in AOD for SouthEast Asia for the period 1980 to 2000 reverse as clean-air strategies come into effect. Both the RCP3-PD but more particularly the RCP8.5 simulations show an increase in AOD in Australia and West Africa because of climate feedbacks that suggest a warmer world will lead to increased dust generation in these areas. The RCP8.5 simulation also shows a significant increase of AOD in polar regions: this is because by 2090 areas of ice-free ocean exist in regions currently covered by sea-ice which allows sea-salt generation.

[25] For RCP3-PD, Figure 6c shows the expected regional brightening associated with the reduced AODs shown in
Figure 6a but there is also some evidence of a more globally uniform dimming resulting in a net global dimming of around $-1 \mathrm{~W} \mathrm{~m}^{-2}$. For RCP8.5, Figure 6d shows that South-East Asia, Europe and the eastern USA are subject to regional brightening or no trend, but these areas are overwhelmed by a large, more homogeneous dimming resulting in a global mean dimming of around $-5.7 \mathrm{~W} \mathrm{~m}^{-2}$. Figure 7 shows a scatterplot of the change in the cloud-free solar SSI as a function of the change in the AOD at $0.55 \mu \mathrm{m}$ for the periods 2090-2000.

[26] Figure 7 shows a similar trend to Figure 2, but there is now a significant offset evident in the intercept of $-5.3 \mathrm{Wm}^{-2}$. Thus while changes in AOD continue to be strongly correlated to changes in the SSI, the offset is due to increases in water vapor in response to the warming. Figures $6 \mathrm{e}$ and $6 \mathrm{f}$ 


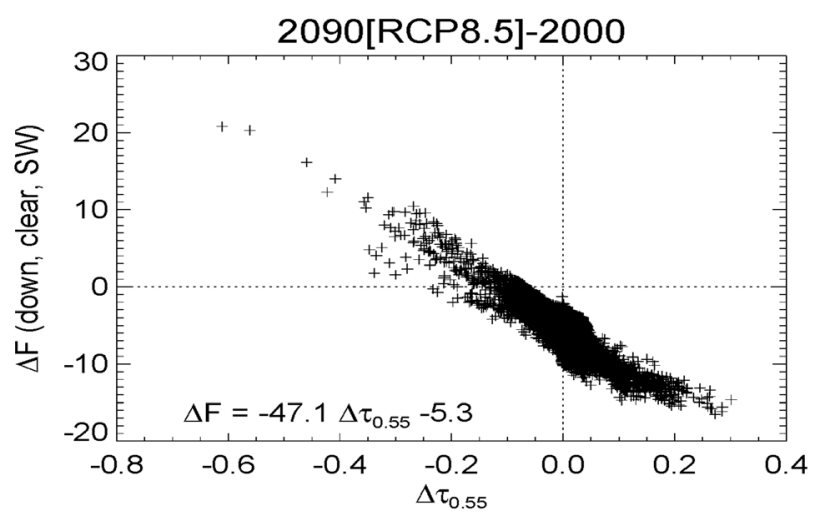

Figure 7. Scatterplots of the change in modeled cloud-free annual-mean SSI ( $\mathrm{W} \mathrm{m}^{-2}$ ) as a function of the change in the AOD ( $\tau 0.55$ ) for the period 2090-2000 under RCP8.5 scenario.

show the change in precipitable water vapor content (PWVC, i.e., the column integrated water vapor in the atmospheric column excluding cloud liquid water and cloud ice water) under the RCP3-PD and RCP8.5 scenarios. PWVC increases by $1.9 \mathrm{~kg} \mathrm{~m}^{-2}(8.5 \%)$ under RCP3-PD and by $7.8 \mathrm{~kg} \mathrm{~m}^{-2}$ (34\%) under RCP8.5, which are much larger changes than those seen before 2000 .

[27] To definitively show that the modeled dimming trend is due to water vapor increases, radiative forcing calculations are performed using double calls to the radiation code at each model radiation time step which allow the radiative impact to be isolated from any feedback effects for both aerosols and water vapor changes. This is achieved by diagnosing the cloud-free SSI at $1860\left(\mathrm{SW}_{\downarrow} 1860\right)$ and performing a second call to the radiation code where the 1860 aerosol field is replaced with that for 2000 to diagnose $\mathrm{SW}_{\downarrow} 2000$ and hence $\left(\mathrm{SW}_{\downarrow} 1860-\mathrm{SW} W_{\downarrow} 2000\right)$. A second set of experiments is performed where the second call to the radiation code is subject to the 2090 aerosol field to diagnose $\left(\mathrm{SW}_{\downarrow} 1860-\mathrm{SW}_{\downarrow} 2090\right) . \quad\left(\mathrm{SW}_{\downarrow} 1860-\mathrm{SW}_{\downarrow} 2000\right)-\left(\mathrm{SW}_{\downarrow} 1860-\right.$ $\left.\mathrm{SW}_{\downarrow} 2090\right)$ yields $\left(\mathrm{SW}_{\downarrow} 2090-\mathrm{SW}_{\downarrow} 2000\right)$ for aerosols. A similar technique is used to diagnose the radiative impact of water vapor. This technique ensures that the atmospheric conditions are held fixed, which is critical in determining the radiative forcing in the absence of feedbacks as described by Forster et al. [2007]. The results are shown in Figure 8.

[28] Figure 8a shows that the radiative impact of decreases in anthropogenic aerosol concentrations amounts to around $+0.95 \mathrm{~W} \mathrm{~m}^{-2}$. Note that because of the technique used in assessing the radiative impact the mineral dust feedbacks that were evident in the increased AOD shown in Figure 6b and the resulting decrease in the cloud-free SSI shown in Figure $6 \mathrm{~d}$ are now absent as expected. The radiative impact of increased concentrations of water vapor is diagnosed at around $-6.1 \mathrm{~W} \mathrm{~m}^{-2}$ which is in good agreement with the $-5.7 \mathrm{~W} \mathrm{~m}^{-2}$ shown in Figure $6 \mathrm{~d}$, when one considers it represents the SSI change caused by changes in concentrations of radiatively active gases (ozone and carbon dioxide will also exert non-negligible impacts on solar radiation) and anthropogenic and natural aerosols. This calculation suggests that these impacts are of second order when compared to the impacts of changes in water vapor. While these changes in cloud-free SSI are calculated using the grid-box mean specific humidity, we also perform calculations where the cloud-free fluxes and changes in SSI are calculated using the specific humidity from the cloud-free portion of the gridbox, but the results show negligible difference to those shown in Figures $8 \mathrm{a}$ and $8 \mathrm{~b}$.

[29] The temporal evolution of the global, European, and South-East Asia cloud-free SSI for the RCP3-PD and RCP8.5 simulations are shown in Figure 9.

[30] Figure 9a shows that for global SSI under RCP3-PD there is little trend in the future indicating that the water vapor dimming is approximately balanced by aerosol-related brightening. However, under RCP8.5 the water vapor dimming clearly outweighs the impact of aerosol brightening leading to an approximately linear dimming trend. The global trend is not found everywhere. Under RCP3-PD brightening prevails in Europe and South-East Asia as the aerosol brightening trend outweighs the water vapor dimming trend. Under RCP8.5 there is a dimming trend over Europe as the water vapor dimming outweighs the aerosol brightening, but
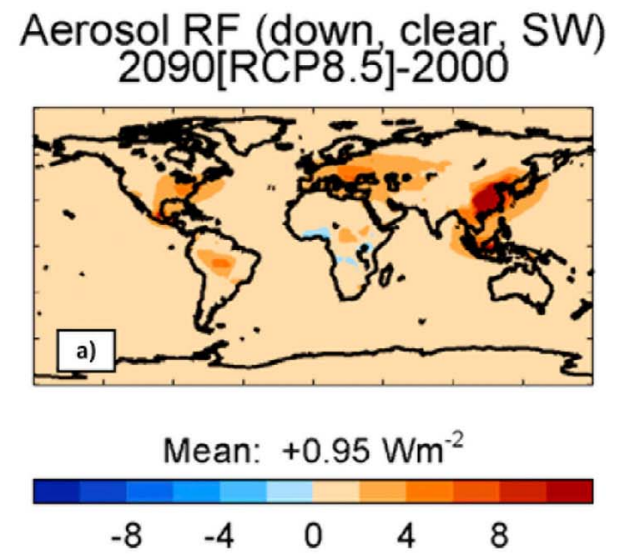

Water vapor RF (down, clear, SW)
2090[RCP8.5]-2000

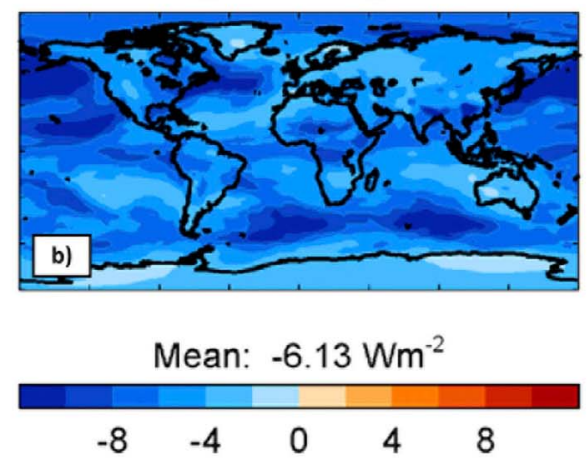

Figure 8. Showing RCP8.5 simulations of cloud-free annual mean (a) modeled radiative impact due to changes in anthropogenic aerosols over the period 2000 to 2090, and (b) the radiative impact due to changes in water vapor over the period 2000 to 2090. 

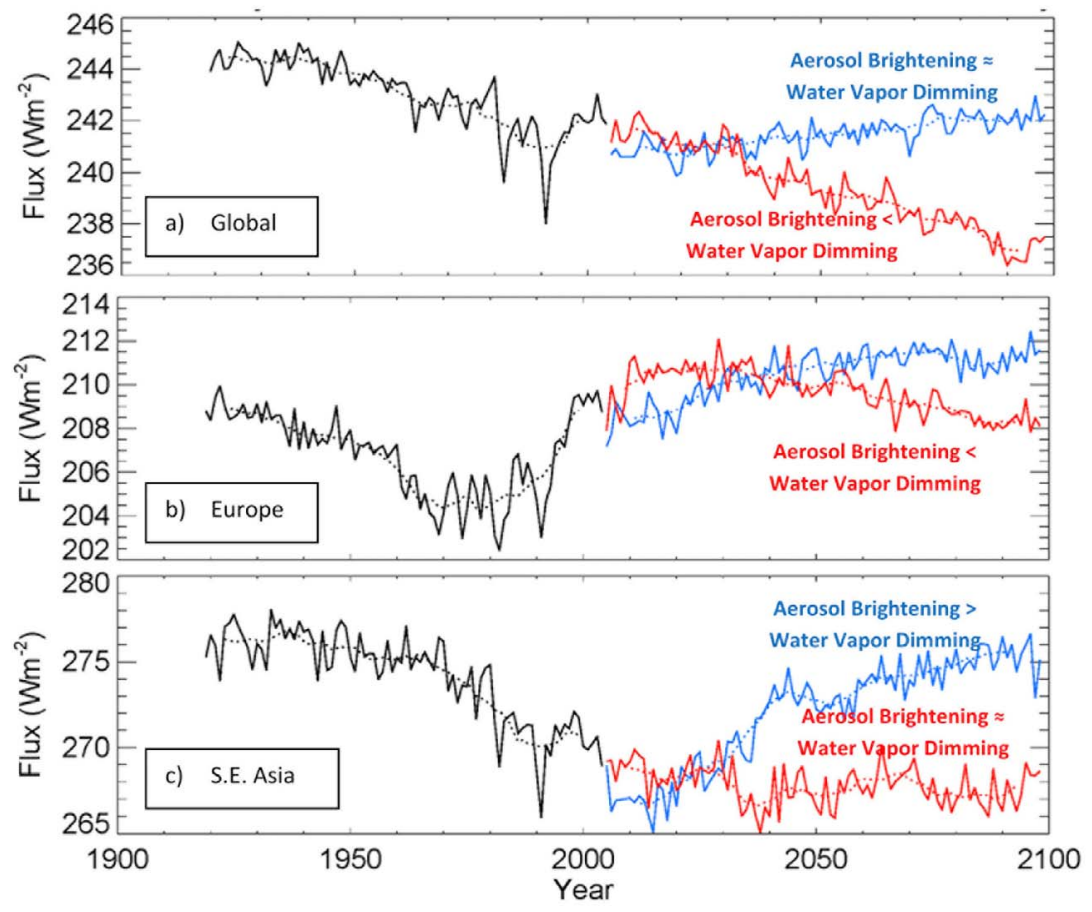

Figure 9. Trends in the cloud-free annual-mean SSI over land for (a) global, (b) Europe, and (c) SouthEast Asia using the areal definitions given in the text. The solid black line shows the historical simulations while the solid blue and red lines show simulations under IPCC RCP3-PD and RCP8.5 scenarios, respectively. The dotted lines show 10-year running means derived from the data.

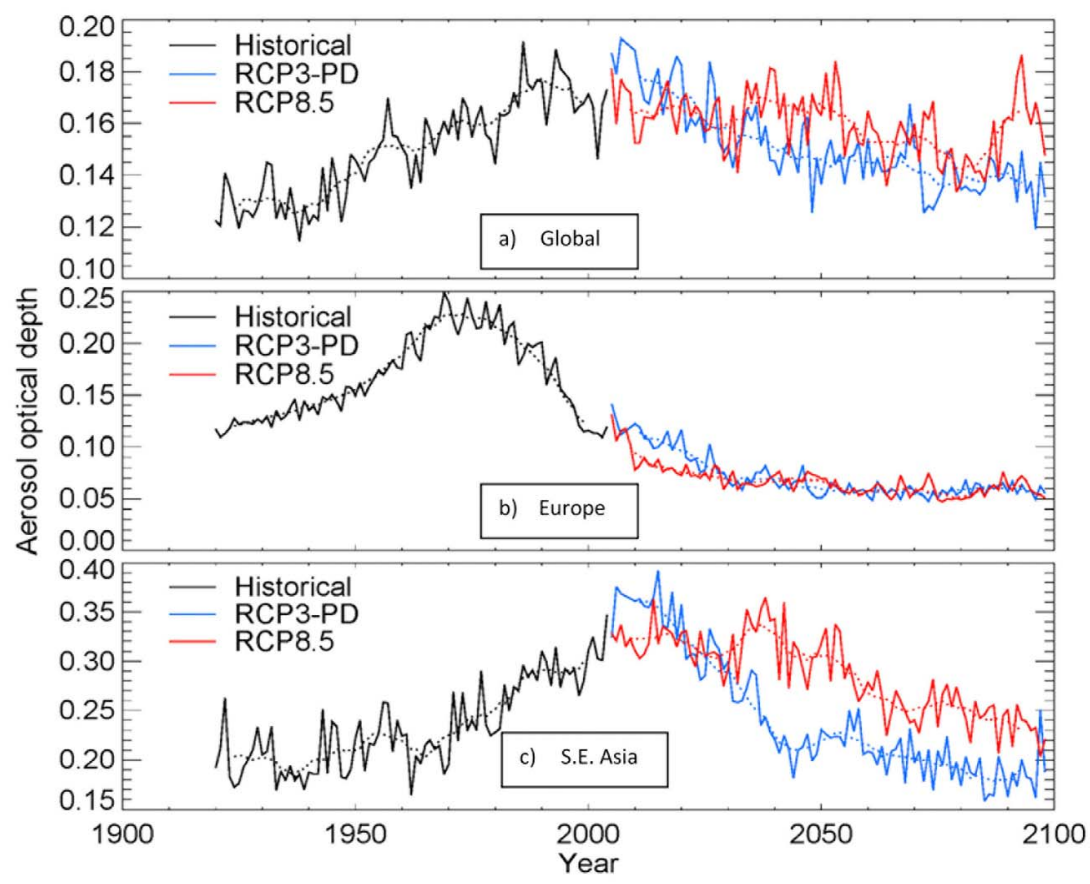

Figure 10. Trends in the annual-mean AOD over land for (a) global, (b) Europe, and (c) South-East Asia using the areal definitions given in the text. The solid black line shows the historical simulations while the solid blue and red lines show simulations under IPCC RCP3-PD and RCP8.5 scenarios, respectively. The dotted lines show 10-year running means derived from the data. 


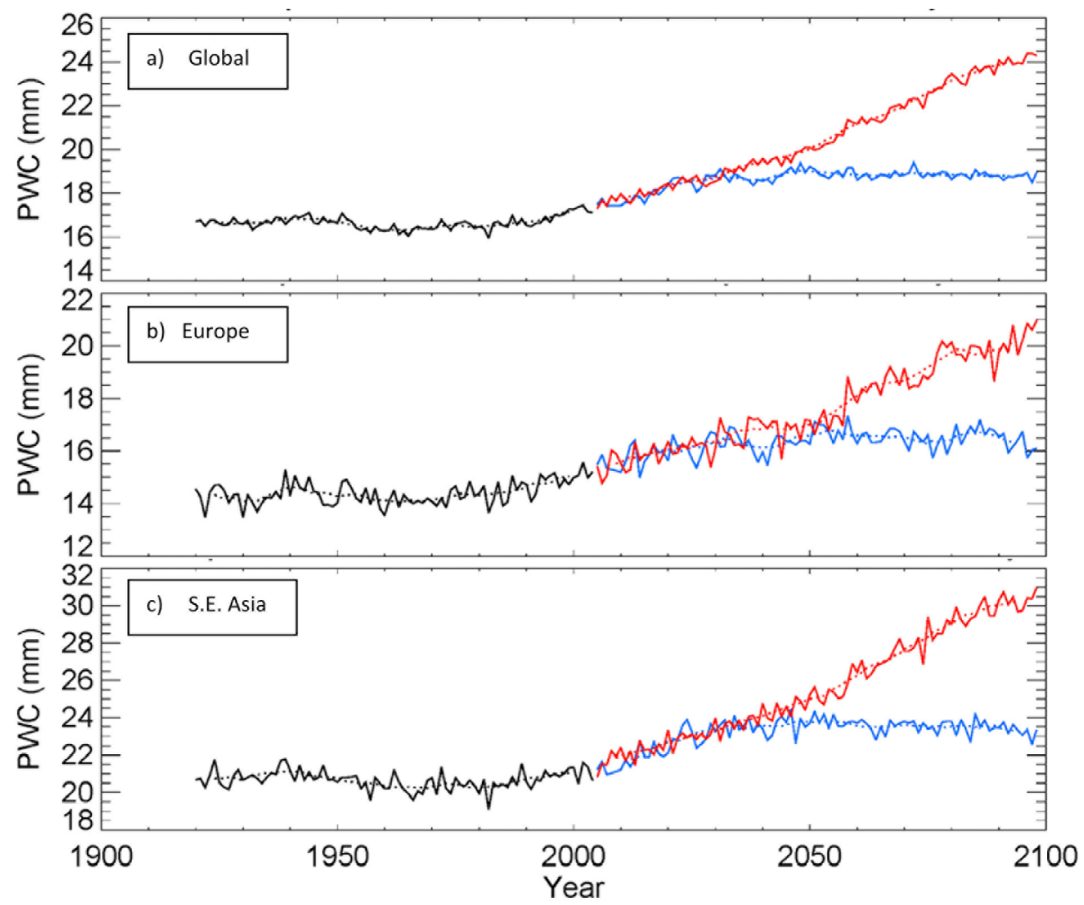

Figure 11. Trends in the modeled annual-mean precipitable water vapor (PWVC) $\mathrm{kgm}^{-2}$ or mm over land for (a) global, (b) Europe, and (c) South-East Asia using the areal definitions given in the text. The solid black line shows the historical simulations while the solid blue and red lines show simulations under IPCC RCP3-PD and RCP8.5 scenarios, respectively. The dotted lines show 10-year running means derived from the data.

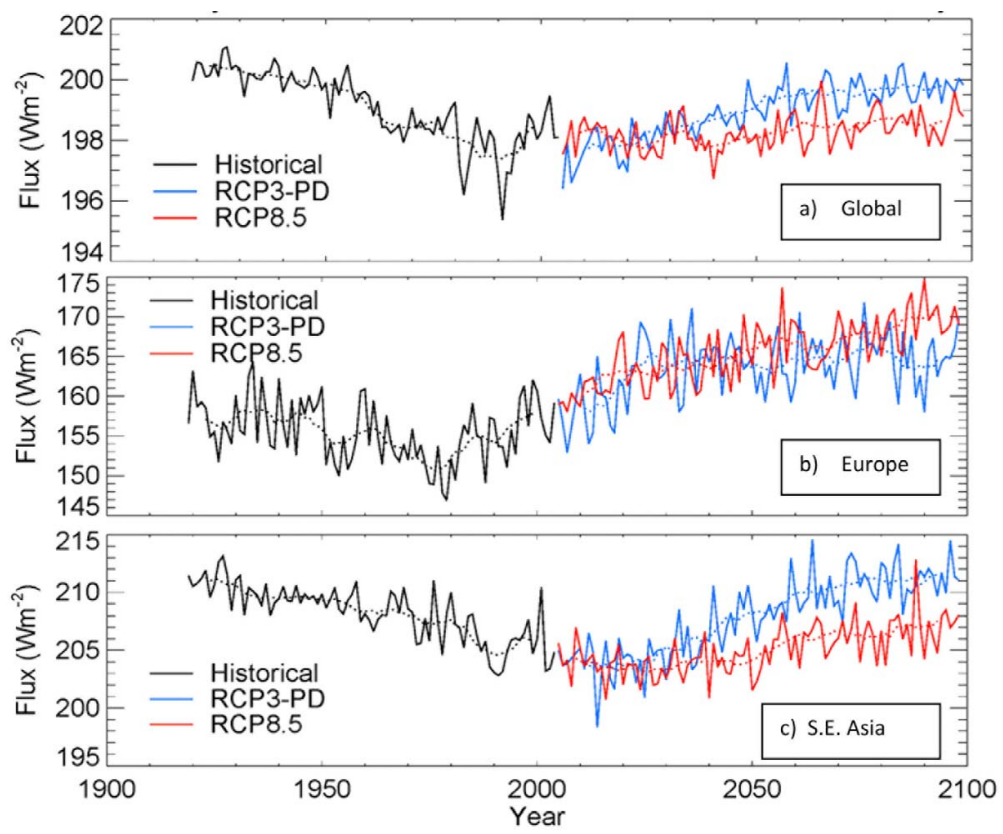

Figure 12. Trends in the total modeled annual-mean SSI over land for (a) global, (b) Europe and (c) SouthEast Asia using the areal definitions given in the text. The solid black line shows the historical simulations while the solid blue and red lines show simulations under IPCC RCP3-PD and RCP8.5 scenarios, respectively. The dotted lines show 10-year running means derived from the data. 


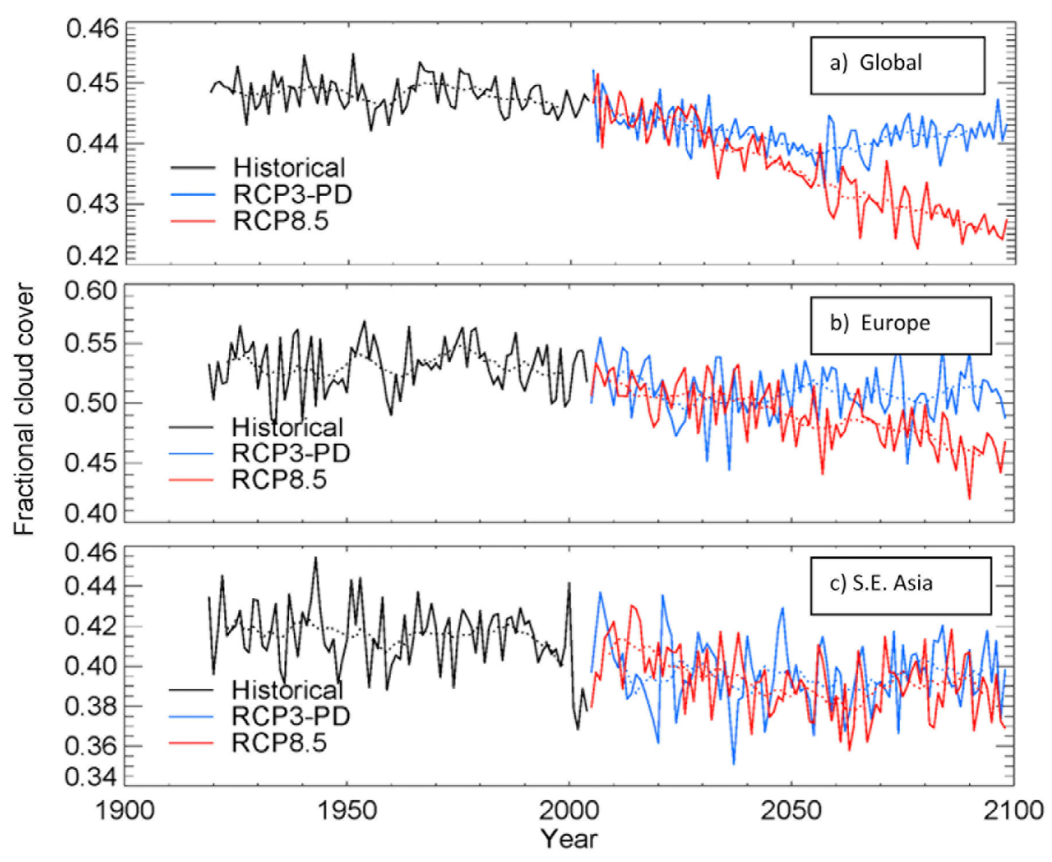

Figure 13. Trends in the modeled annual-mean fractional cloud cover for (a) global, (b) Europe and (c) South-East Asia using the areal definitions given in the text. The solid black line shows the historical simulations while the solid blue and red lines show simulations under IPCC RCP3-PD and RCP8.5 scenarios, respectively. The dotted lines show 10 -year running means derived from the data.

over South-East Asia the water vapor dimming is approximately balanced by the aerosol brightening. The interpretation of these trends is backed up by the trends in the global, European and SE. Asian AOD and PWVC that are shown in Figure 10 and Figure 11.

[31] Figure 10 shows relatively minor trends in the AOD during the 21 st century, while Figure 11 shows a significant almost linear PWVC trend across global, European, and SE. Asian regions for the RCP8.5 scenario.

[32] Figure 12 shows that the cloud-free trends are not evident in the total SSI. Overall little trend is observed in the global total SSI (Figure 12a). Europe shows that the brightening that started around 1980 (minimum of around $150-155 \mathrm{~W} \mathrm{~m}^{-2}$ ) continues through to 2090 (maximum of around $165-170 \mathrm{~W} \mathrm{~m}^{-2}$ ) depending on the RCP scenario. The trends in South-East Asia show a less pronounced brightening than Europe. This brightening cannot be to aerosol changes as the magnitude of the total irradiance trend far exceeds that of the cloud-free irradiance trend (Figure 9b) but is due to changes in the cloud cover, shown in Figure 13.

[33] The reason for this very different behavior between the cloud-free and total SSI lies in the changes in the cloud cover, which are shown in Figure 13.

[34] Figure 13a shows that the global cloud cover (over land areas) under the RCP8.5 scenario reduces. This reduction in cloud cover is sufficient to mask the change in the cloud-free SSI (Figure 9a) and ensure that the trend in the total SSI is small (Figure 12a). Over Europe, the changes under RCP8.5 are even more dramatic: cloud cover reduces by from around $52 \%$ to $46 \%$ between 2000 and 2100 (Figure 13b) which again masks the cloud-free dimming trend due to water vapor increases (Figure 11b). Bellouin et al.
[2011] provides a more detailed analysis in the changes in the latitudinal and vertical profile of clouds between 2000 and 2100 .

\section{Discussion and Conclusions}

[35] On a global average basis, the impact of the volcanic eruptions of Agung, El Chichón and Pinatubo are clearly discernable in the modeled cloud-free and total SSI. These volcanic eruptions cause some of the statistically significant dimming trends in the model cloud-free SSI during the 1960s and 1980s. The impacts of these volcanic eruptions are also documented in the observational records. Globally, HIST suggests an overall dimming in cloud-free and total SSI of around -2 to $-3 \mathrm{~W} \mathrm{~m}^{-2}$ over the period 1920-2000, with some evidence of a minimum SSI around 1980s-1990s and a small subsequent brightening.

[36] Regional dimming and brightening trends are most comprehensively documented over Europe, where a dimming is observed pre-1980s, followed by a brightening post-1980s [Wild, 2009]. Arguably, the most comprehensive single study of the dimming and brightening trends over Europe is that of Norris and Wild [2007] who analyze data from 75 surface sites and diagnose a dimming between 1971 and 1986 of -2.7 to $-3.5 \mathrm{~W} \mathrm{~m} \mathrm{~W}^{-2} /$ decade followed by a brightening between 1987 and 2002 of 2.0 to $2.3 \mathrm{~W} \mathrm{~m}^{-2}$ /decade. Other studies suggest dimming trends of up to $-8 \mathrm{Wm}^{-2} /$ decade pre- $1980 \mathrm{~s}$ with brightening trends of up to $4.9 \mathrm{~W} \mathrm{~m}^{-2}$ /decade thereafter. The peak dimming in HIST is statistically significant from 1968 to 1977 where the dimming exceeds $-3.1 \mathrm{~W} \mathrm{~m}^{-2}$ /decade, while statistically significant brightenings exceeding $4 \mathrm{~W} \mathrm{~m}^{-2}$, decade are evident in the model during the 1980s and 1990s. 
Thus modeled trends in dimming and brightening over Europe appear reasonably represented by HadGEM-2 when the model is driven by historical emission data. If only changes in the cloud-free SSI are considered, the model simulations tend to underestimate these trends. However, if the impacts of changes in clouds are also considered, the model simulations tend to be in better agreement (Figure 5). In the model, the aerosol indirect effect parameterization will lead to reduced cloud droplet size, which will reflect more solar radiation to space leading to a decrease in SSI (first indirect effect [Haywood and Boucher, 2000]). The reduced cloud droplet size also tends to suppress autoconversion and precipitation, leading to an increase in cloud liquid water content and fractional cloud cover (second indirect effect [Haywood and Boucher, 2000]). Thus, the indirect effect may play an important role in explaining the observed trends in dimming and brightening. These results contrast with those of Wild and Schmucki [2011], who analyzed IPCC 4AR models and concluded that the (all-sky) observations correlated better with the model-simulated cloud-free SSI than with the all-sky SSI on decadal time scales. These differences in model behavior suggest that there is clearly more room for in depth analysis. We also acknowledge that a more detailed study and more complex experimental design would be required to determine whether the indirect effect does indeed play an important role over Europe: the impacts of cloud feedbacks and/or natural variability in clouds, or inaccurate representation of changes in aerosol emissions, could also be important factors.

[37] Over South-East Asia, the model suggests an overall dimming trend exists until 1990 independently of whether cloud-free or total SSI are considered, while the observations of total SSI suggest a clear dimming trend. Analysis of the PDF of model trends for total SSI suggests that either dimming or brightening may occur post-1990, which is consistent with the observations.

[38] Projections of future changes show the cloud-free SSI is strongly dependent on the chosen scenario. However, perhaps surprisingly, these trends are not primarily related to changes in aerosol concentrations but to changes in atmospheric concentrations of water vapor. Under RCP8.5, by 2090 the PWVC in HadGEM2-ES has increased by almost $35 \%$, leading to a significant dimming in the cloud-free SSI of around $-6 \mathrm{~W} \mathrm{~m}^{-2}$. As the water vapor feedback in climate models is relatively well constrained [Randall et al., 2007; Soden and Held, 2006] one would therefore expect the primary driver of the trend in cloud-free SSI to be the model climate sensitivity: models with high climate sensitivities will have high temperature increases and relatively large increases in PWVC and vice versa. Hence we would expect our findings to be robust in other models, but modulated by the model climate sensitivity. Tests with the HADGEM2-ES model suggest that the temperature change under RCP 8.5 by 2100 is around $+5.2 \mathrm{~K}$. Garrat et al. [1999] briefly drew attention to predicted changes in SSI due to increases in water vapor, as $\mathrm{CO}_{2}$ amounts increased, in a range of climate models, deriving values consistent with those shown for clear skies, although the all-sky value was heavily dependent on the nature of the cloud feedbacks in particular models. Unlike the water vapor response, the cloud response, and hence the change in total SSI, is likely to be much more variable between different climate models. Of course, our analysis is unable to predict the impact of any future volcanic eruptions. Recent analysis of space-borne limb-sounding and lidar data has shown a small, but significant increase in stratospheric AODs during the period 2000-2010 owing to increased impact of relatively small volcanic eruptions [Haywood et al., 2010; Vernier et al., 2011; Solomon et al., 2011].

[39] Note that the spectral variation in the dimming/ brightening caused by aerosols, water vapor and cloud changes will differ markedly. Accumulation-mode anthropogenic aerosols will scatter and absorb solar radiation more at short wavelengths than longer wavelengths [e.g., Haywood and Boucher, 2000], the precise details being dependent on the size distribution and refractive index of the particles. Water vapor absorbs at longer wavelengths, with the stronger absorption bands starting at around 0.7 through to $4 \mu \mathrm{m}$. Clouds will impact solar radiation across the entire solar spectrum. Therefore aerosol dimming/brightening will have the largest impact at ultraviolet and visible wavelengths, water vapor dimming/brightening will impact near infrared wavelengths, and cloud will have an impact across all wavelengths. The impact of the predicted changes on marine and terrestrial ecosystems is likely to be strongly dependent on the way any dimming/brightening varies with wavelength; hence the wavelength-integrated changes may not be a good indicator of any wider impacts.

[40] An uncertainty in estimating the impact of water vapor changes on the SSI, comes from evolving understanding of the strength (and causes) of absorption in the relatively transparent near-infrared window regions. Recent laboratory measurements have shown that water vapor self-continuum models used within GCMs likely underestimate this absorption by around an order of magnitude [Baranov and Lafferty, 2011; Ptashnik et al., 2011]. This not only affects the SSI in the control simulations but, because the continuum absorption scales as the square of the vapor pressure, it could affect the change in SSI as water vapor concentrations increase. One early, simplified, estimate of the impact of increased absorption in these window regions estimated an increased absorption, as a result of a $2 \mathrm{~K}$ increase in temperature, reaching several tenths of a $\mathrm{W} \mathrm{m}^{-2}$ in the tropics [Vaida et al., 2001]. Clearly, improved estimates, based on the recent laboratory studies are needed to achieve a better quantification.

[41] Finally, while this study has focused on the modeled changes in the historical and future solar dimming/brightening trends at the surface, we acknowledge that we are not giving a full picture of the changes in all of the components of the energy budget. Increases in the water vapor under RCP3-PD and RCP 8.5 by 2090 increase the total downwelling surface long-wave terrestrial irradiances by 5 and $16 \mathrm{~W} \mathrm{~m}^{-2}$, respectively, changes that far outweigh the changes in the solar component of the radiation budget that we have examined here.

[42] We conclude that while historical changes in the total SSI are likely due to aerosols via direct and indirect effects, future changes in the cloud-free SSI will be dominated by increases in water vapor concentrations resulting from the water vapor feedback. While it is widely appreciated that water vapor is a strong and effective greenhouse gas, the impacts upon the solar spectrum are frequently overlooked. 
[43] Acknowledgments. J.M.H., O.B., A.J., and N.B. acknowledge support from DECC/Defra Integrated Climate Programme. K.P.S. acknowledges support from the NERC/EPSRC funded consortium CAVIAR. Chris D. Jones of the Met Office Hadley Centre is thanked for providing a description of the CMIP5 emission scenarios.

\section{References}

Baranov, Y. I., and W. J. Lafferty (2011), The water-vapor continuum and selective absorption in the 3 to $5 \mu \mathrm{m}$ spectral region at temperatures from 311 to 363 K, J. Quant. Spectrosc. Radiat. Transfer, 112, 1304-1313, doi:10.1016/j.jqsrt.2011.01.024.

Bellouin, N., A. Jones, J. M. Haywood, and S. A. Christopher (2008), Updated estimate of aerosol direct radiative forcing from satellite observations and comparison against the Hadley Centre climate model, J. Geophys. Res., 113, D10205, doi:10.1029/2007JD009385.

Bellouin, N., J. Rae, A. Jones, C. Johnson, J. Haywood, and O. Boucher (2011), Aerosol forcing in the CMIP5 simulations by HadGEM2-ES and the role of ammonium nitrate, J. Geophys. Res., doi:10.1029/ 2011JD016074, in press.

Cionni, I., V. Eyring, J.-F. Lamarque, W. J. Randel, D. S. Stevenson, F. Wu, G. E. Bodeker, T. G. Shepherd, D. T. Shindell, and D. W. Waugh (2011), Ozone database in support of CMIP5 simulations: Results and corresponding radiative forcing, Atmos. Chem. Phys. Discuss., 11, $10,875-10,933$.

Collins, W. J., et al. (2011), Development and evaluation of an Earthsystem model-HadGEM2, Geosci. Model Dev. Discuss., 4, 997-1062, doi:10.5194/gmdd-4-997-2011.

Edwards, J. M., and A. Slingo (1996), Studies with a flexible new radiation code. I: Choosing a configuration for a large-scale model, $Q$. J. R. Meteorol. Soc., 122, 689-719, doi:10.1002/qj.49712253107.

Forster, P., et al. (2007), Changes in atmospheric constituents and in radiative forcing, in Climate Change 2007: The Physical Science Basis. Contribution of Working Group I to the Fourth Assessment Report of the Intergovernmental Panel on Climate Change, edited by S. Solomon et al., pp. 129-224, Cambridge Univ. Press, Cambridge, U. K.

Garrat, J. R., D. M. O'Brien, M. R. Dix, J. M. Murphy, G. L. Stephens, and M. Wild (1999), Surface radiation flux in transient climate simulations, Global Planet. Change, 20, 33-55.

Gilgen, H., M. Wild, and A. Ohmura (1998), Means and trends of shortwave irradiance at the surface estimated from GEBA, J. Clim., 11, 2042-2061, doi:10.1175/1520-0442-11.8.2042.

Gray, L. J., S. T. Rumbold, and K. P. Shine (2009), Stratospheric temperatures and radiative forcing response to 11-year solar cycle changes in irradiance and ozone, J. Atmos. Sci., 66, 2402-2417, doi:10.1175/ 2009JAS2866.1.

Haywood, J. M., and O. Boucher (2000), Estimates of the direct and indirect radiative forcing due to tropospheric aerosols: A review, Rev. Geophys., 38, 513-543, doi:10.1029/1999RG000078.

Haywood, J. M., et al. (2010), Observations of the eruption of the Sarychev volcano and simulations using the HadGEM2 climate model, J. Geophys. Res., 115, D21212, doi:10.1029/2010JD014447.

Hurtt, G. C., et al. (2011), Harmonization of land-use scenarios for the period 1500-2100: 600 years of global gridded annual land-use transitions, wood harvest, and resulting secondary lands, Clim. Change, doi:10.1007/s10584-011-0153-2, in press.

Jones, A., D. L. Roberts, M. J. Woodage, and C. E. Johnson (2001), Indirect sulphate aerosol forcing in a climate model with an interactive sulphur cycle, J. Geophys. Res., 106, 20,293-20,310, doi:10.1029/ 2000JD000089.

Jones, C. D., et al. (2011), The HadGEM2-ES implementation of CMIP5 centennial simulations, Geosci. Model Dev. Discuss., 4, 689-763, doi:10.5194/gmdd-4-689-2011. [Available at www.geosci-model-devdiscuss.net/4/689/2011/.]

Kvalevåg, M. M., and G. Myhre (2007), Human impact on direct and diffuse solar radiation during the industrial era, J. Clim., 20, 4874-4883, doi:10.1175/JCLI4277.1.

Lamarque, J.-F., et al. (2010), Historical (1850-2000) gridded anthropogenic and biomass burning emissions of reactive gases and aerosols Methodology and application, Atmos. Chem. Phys., 10, 7017-7039, doi:10.5194/acp-10-7017-2010.

Liepert, B. G. (2002), Observed reductions of surface solar radiation at sites in the United States and worldwide from 1961 to 1990, Geophys. Res. Lett., 29(10), 1421, doi:10.1029/2002GL014910.

Meinshausen, M., et al. (2011), The RCP greenhouse gas concentrations and their extension from 1765 to 2300, Clim. Change, doi:10.1007/ s10584-011-0156-z, in press.
Moss, R. H., et al. (2010), The next generation of scenarios for climate change research and assessment, Nature, 463, 747-756, doi:10.1038/ nature 08823 .

Norris, J. R., and M. Wild (2007), Trends in direct and indirect aerosol radiative effects over Europe inferred from observed solar dimming and brightening, J. Geophys. Res., 112, D08214, doi:10.1029/2006JD007794.

Ohmura, A., and H. Lang (1989), Secular variation of global radiation over Europe, in Current Problems in Atmospheric Radiation, edited by J. Lenoble and J. F. Geleyn, pp. 98-301, A. Deepak, Hampton, Va.

Padma Kumari, B., A. L. Londhe, S. Daniel, and D. B. Jadhav (2007), Observational evidence of solar dimming: Offsetting surface warming over India, Geophys. Res. Lett., 34, L21810, doi:10.1029/2007GL031133.

Ptashnik, I. V., R. A. McPheat, K. P. Shine, K. M. Smith, and R. G. Williams (2011), Water vapour self-continuum absorption in nearinfrared windows, derived from laboratory measurements, J. Geophys. Res., 116, D16305, doi:10.1029/2011JD015603.

Randall, D. A., et al. (2007), Climate models and their evaluation, in Climate Change 2007: The Physical Science Basis. Contribution of Working Group I to the Fourth Assessment Report of the Intergovernmental Panel on Climate Change, edited by S. Solomon et al., pp. 589-662, Cambridge Univ. Press, Cambridge, U. K.

Romanou, A., B. Liepert, G. A. Schmidt, W. B. Rossow, R. A. Ruedy, and Y. Zhang (2007), 20th century changes in surface solar irradiance in simulations and observations, Geophys. Res. Lett., 34, L05713, doi:10.1029/2006GL028356.

Sato, M., J. E. Hansen, M. P. McCormick, and J. B. Pollack (1993), Stratospheric aerosol optical depths, 1850-1990, J. Geophys. Res., 98, 22,987-22,994, doi:10.1029/93JD02553.

Soden, B. J., and I. M. Held (2006), An assessment of climate feedbacks in coupled ocean-atmosphere models, J. Clim., 19, 3354-3360, doi:10.1175/JCLI3799.1.

Solomon, S., J. S. Daniel, R. R. Neely III, J. P. Vernier, E. G. Dutton, and L. W. Thomason (2011), The persistently variable "background" stratospheric aerosol layer and global climate change, Science, 333(6044), 866-870, doi:10.1126/science.1206027.

Stanhill, G., and S. Cohen (2001), Global dimming: A review of the evidence for a widespread and significant reduction in global radiation, Agric. For. Meteorol., 107, 255-278, doi:10.1016/S0168-1923(00) 00241-0.

Stanhill, G., and S. Cohen (2008), Solar radiation changes in Japan during the 20th century: Evidence from sunshine duration measurements, J. Meteorol. Soc. Jpn., 86(1), 57-67.

Stanhill, G., and J. D. Kalma (1995), Solar dimming and urban heating in Hong Kong, Int. J. Climatol., 15, 933-941, doi:10.1002/joc.3370150807.

Vaida, V., J. S. Daniel, H. G. Kjaergaard, L. M. Goss, and A. F. Tuck (2001), Atmospheric absorption of near infrared and visible solar radiation by the hydrogen bonded water dimer, $Q$. J. R. Meteorol. Soc., 127, 1627-1643, doi:10.1002/qj.49712757509.

Vernier, J.-P., et al. (2011), Major influence of tropical volcanic eruptions on the stratospheric aerosol layer during the last decade, Geophys. Res. Lett., 38, L12807, doi:10.1029/2011GL047563.

Weatherhead, E. C., A. J. Stevermer, and B. E. Schwartz (2002), Detecting environmental changes and trends, Phys. Chem. of Earth, Parts $A / B / C$, 27(6), 399-403, doi:10.1016/S1474-7065(02)00019-0.

Wild, M. (2009), Global dimming and brightening: A review, J. Geophys. Res., 114, D00D16, doi:10.1029/2008JD011470.

Wild, M., and E. Schmucki (2011), Assessment of global dimming and brightening in IPCC-AR4/CMIP3 models and ERA40, Clim. Dyn., doi:10.1007/s00382-010-0939-3, in press.

Wild, M., et al. (2005), From dimming to brightening: Decadal changes in surface solar radiation, Science, 308,847-850, doi:10.1126/ science. 1103215 .

Wild, M., B. Trussel, A. Ohmura, C. N. Long, E. G. Dutton, G. KonigLanglo, and A. Tsvetkov (2009), Global dimming and brightening: An update beyond 2000, J. Geophys. Res., 114, D00D13, doi:10.1029/ 2008JD011382.

Woodward, S. (2001), Modelling the atmospheric life cycle and radiative impact of mineral dust in the Hadley Centre climate model, J. Geophys. Res., 106(D16), 18,155-18,166, doi:10.1029/2000JD900795.

N. Bellouin, O. Boucher, J. M. Haywood, and A. Jones, Hadley Centre, Met Office, Fitzroy Road, Exeter EX1 3PB, UK. (jim.haywood@metoffice. gov.uk)

K. P. Shine, Department of Meteorology, University of Reading, Earley Gate, PO Box 243, Reading RG6 6BB, UK.

M. Wild, Institute for Atmospheric and Climate Science, ETH Zurich, Universitaetsstr. 16, Zurich CH-8092, Switzerland. 